\title{
Philosophiques
}

\section{Chiara Crisciani et Claude Gagnon. Alchimie et philosophie au moyen âge. Montréal, l'Aurore/Univers, 1980, 83 p.}

\section{Louis-Claude Paquin}

Volume 8, numéro 2, octobre 1981

URI : https://id.erudit.org/iderudit/203177ar

DOI : https://doi.org/10.7202/203177ar

Aller au sommaire du numéro

Éditeur(s)

Société de philosophie du Québec

ISSN

0316-2923 (imprimé)

1492-1391 (numérique)

Découvrir la revue

Citer ce compte rendu

Paquin, L.-C. (1981). Compte rendu de [Chiara Crisciani et Claude Gagnon. Alchimie et philosophie au moyen âge. Montréal, l'Aurore/Univers, 1980, 83 p.] Philosophiques, 8(2), 356-357. https://doi.org/10.7202/203177ar d'utilisation que vous pouvez consulter en ligne.

https://apropos.erudit.org/fr/usagers/politique-dutilisation/ 
Chiara CRISCIANI et Claude GAGNON. Alchimie et philosophie au moyen âge. Montréal, l'Aurore/Univers, 1980, 83 p.

par Louis-Claude Paquin

En quoi l'alchimie peut-elle contribuer à une meilleure compréhension de la philosopbie médiévale?

Telle était la question posée aux deux auteurs du présent ouvrage par le président de la Commission d'Histoire des Sciences pour leur communication au $V I^{\mathrm{e}}$ congrès de la Société Internationale pour l'Étude de la Pbilosophie Médiévale, tenu à Bonn en 1977. Ils ont senti le besoin d'aller plus loin dans leur démarche et de synthétiser à la fois la problématique alchimique et la documentation disponible. Si la formule littéraire retenue par les auteurs est celle d'une bibliographie raisonnée, c'est qu'elle est le prétexte à un foisonnement d'informations, de références et d'hypothèses. En effet, cet ouvrage tient plus du questionnement multidisciplinaire que de la monographie bien ordonnée, et c'est ce qui fait son intérêt.

Bien que l'alchimie n'ait été que très peu étudiée rigoureusement depuis l'avènement des historiographies modernes de la philosophie médiévale, elle n'a jamais cessé d'exercer une fascination sur les intellectuels; les deux auteurs reprennent d'une façon critique les études antérieures et n'hésitent pas à 
prendre des positions polémiques, s'appuyant sur des discours critiques contemporains tels l'épistémologie, la sociologie et le structuralisme. Afin de renouveler la problématique, les auteurs choisissent d'abolir l'opposition théorique traditionnelle entre le discours alchimique et le discours scolastique alors dominant; ils remplacent toutefois cette notion d'écart par des critères assez vagues: les sélecteurs épistémiques. Ils abandonnent l'idée positiviste selon laquelle l'alchimie serait une erreur temporaire qui mène à la chimie scientifique. La problématique de la spécificité des textes alchimiques qu'ils élaborent est plurielle et ouverte, tenant compte de la diversité des traités et des recueils de recettes. Leur approche est multiple. Ainsi l'alchimie est tour à tour liée à la spéculation aurifere, à l'aritotélisme et au néoplatonisme, à la théologie chrétienne, à la magie arabe, à la littérature (Le Roman de la Rose).

Ils soulignent ensuite l'important travail qu'il reste à accomplir dans le corpus alchimique médiéval (travail ardu en raison des apocryphes et des fausses attributions): étudier les enchevêtrements de paraphrases, citations, commentaires et autres ajouts qui produisent un texte nouveau, étudier la métaphorisation qui établit des rapports et des correspondances. Puis, successivement, ils tentent de définir l'alchimie; ils étudient la discussion philosophique-scolastique sur l'alchimie de Petrus Bonus Pretiosa Margarita Novella (XIV ${ }^{\mathrm{e}}$ siècle); ils donnent un portrait épistémologique de l'alchimiste; ils isolent les procédés du discours alchimique: co-implication, analogie, synthèse; enfin, ils étudient les motifs de l'exclusion de ce discours.

Cet ouvrage succinct est un ensemble d'hypothèses et d'interrogations dont la hardiesse indéniable ne nous empèche pas de regretter toutefois la presque absence de développement de preuves et d'élucidations du contexte des textes alchimiques médiévaux. En effet, les auteurs se réferent plutôt aux incunables, aux éditions de la Renaissance et même postérieures quaux manuscrits médiévaux authentiques; ces éditions sont malheureusement sans rigueur. On nous apprend en somme comment aborder légitimement la question alchimique, mais on ne cerne pas la spécificité de l'alchimie médiévale.

C'est un livre à lire par ceux qui ont envie d'épistémologie ou ceux qui veulent dépasser «l'ésotérisme mercantile» qui entoure l'alchimie depuis la Renaissance. Ceux qui veulent connaître l'histoire de l'alchimie médiévale devront cependant attendre des études basées sur des éditions critiques.

Institut d'études médiévales

Université de Montréal 